\title{
Immortalized ovarian surface epithelial cells acquire tumorigenicity by Acrogranin gene overexpression
}

\author{
MASANORI MIYANISHI, MASAKI MANDAI, NORIOMI MATSUMURA, KEN YAMAGUCHI, \\ JUNZO HAMANISHI, TOSHIHIRO HIGUCHI, KENJI TAKAKURA and SHINGO FUJII
}

\author{
Department of Gynecology and Obstetrics, Graduate School of Medicine, Kyoto University, Kyoto 606-8507, Japan
}

Received August 25, 2006; Accepted October 9, 2006

\begin{abstract}
Malignant transformation is caused by multi-step genetic mutations, and growth factors are believed to play important roles in developing and maintaining malignant phenotype. However, there is no direct evidence that a specific growth factor contributes to malignant transformation of phenotypically normal cells. In order to assess the function of Acrogranin (also known as granulin epithelial precursor; GEP) in ovarian carcinogenesis, ovarian surface epithelial (OSE) cells, which are supposed to be the origin of primary ovarian epithelial cancer, were transfected with combined genes of hTERT, SV40 LT, and Acrogranin. Introduction of hTERT and SV40 LT was sufficient for immortalizing OSE cells but not enough for tumor formation in nude mice. In contrast, transfection and overexpression of Acrogranin in immortalized OSE cells showed augmented clonogenicity in soft agar and obvious tumorigenicity in nude mice. This is the first study showing evidence that a specific growth factor plays a direct role in malignant transformation in ovarian cancer development.
\end{abstract}

\section{Introduction}

Malignant tumor develops as a result of stepwise accumulation of various genetic alterations such as mutation, amplification or silencing. Although a number of gene abnormalities have been detected so far, it is not necessarily clear if all the aberrancy is inevitable in cancer development. Some of the growth factors such as TGF- $\beta$, M-CSF or LPA and their receptor-mediated signalings are known to play important roles in cancer cell biology. Nevertheless, their role and contribution to cancer development are not fully elucidated $(1,2)$. Acrogranin, which is also designated as granulin epithelial precursor (GEP), PC cell-derived growth factor, progranulin or proepithelin, is an $88-\mathrm{kDa}$ glycoprotein that

Correspondence to: Dr Masaki Mandai, Department of Gynecology and Obstetrics, Graduate School of Medicine, Kyoto University, Kyoto 606-8507, Japan

E-mail: mandai@kuhp.kyoto-u.ac.jp

Key words: Acrogranin, ovarian cancer, tumorigenicity was identified as a growth factor secreted from a murineteratoma cell, PC $(3,4)$. Physiologically, Acrogranin plays a significant role in development and wound repair $(5,6)$. It has also been reported that Acrogranin is overexpressed in various types of malignant tumors such as glioma, breast, prostate, liver and ovarian cancers (7-12). Experimentally, overexpression of Acrogranin in cancer cell lines results in enhanced proliferation, and inhibition of the gene expression impairs cell growth. However, there is no direct evidence that overexpression of Acrogranin contributes to malignant transformation.

Ovarian cancer is the most lethal of all the gynecological malignancies, being responsible for $\sim 50 \%$ of all the deaths in female genital tract cancer. Since the majority $(75-80 \%)$ of ovarian cancer patients presents at an advanced-stage, little is known about the early genetic events that are involved in the development of this disease, despite a number of genetic abnormalities were found in fully developed ovarian cancer. We have previously established a method to evaluate the influence of these genetic abnormalities on ovarian canrcinogenesis, in which OSE, a putative origin of ovarian cancer, was tranfected with several cancer-related genes and examined the tumorigenicity in nude mice. We found that transfection of hTERT, SV40 LT, and c-ERBB2 or mutant Ha-RAS were sufficient for the transformation of OSE (13). In this study, by using the same method, we show the first direct evidence that Acrogranin contributes to malignant transformation of OSE.

\section{Materials and methods}

Immunohistochemical staining for Acrogranin. Samples (16 cases of carcinoma composed of 4 stage I, 10 stage III, and 1 stage IV cases, and 13 LMP cases were all stage I) were obtained in surgical procedure and used with written consent under approval of the Ethics Committee of Kyoto University Hospital. Tissues were fixed in $10 \%$ phosphate-buffered formalin, dehydrated in ethanol, embedded in paraffin and sectioned. Samples were deparaffinized in xylene and ethanol and then retrieved with Target retrieval solution high $\mathrm{PH}$ (Dako Cytomation, Tokyo) for $15 \mathrm{~min}$ at $95^{\circ} \mathrm{C}$. Then samples were blocked for endogenous peroxidase with $0.3 \%$ $\mathrm{H}_{2} \mathrm{O}_{2} /$ methanol for $15 \mathrm{~min}$, followed by sequential incubation with normal rabbit serum for $30 \mathrm{~min}$ at room temperature, primary antibody (a goat polyclonal anti-Acrogranin antibody 


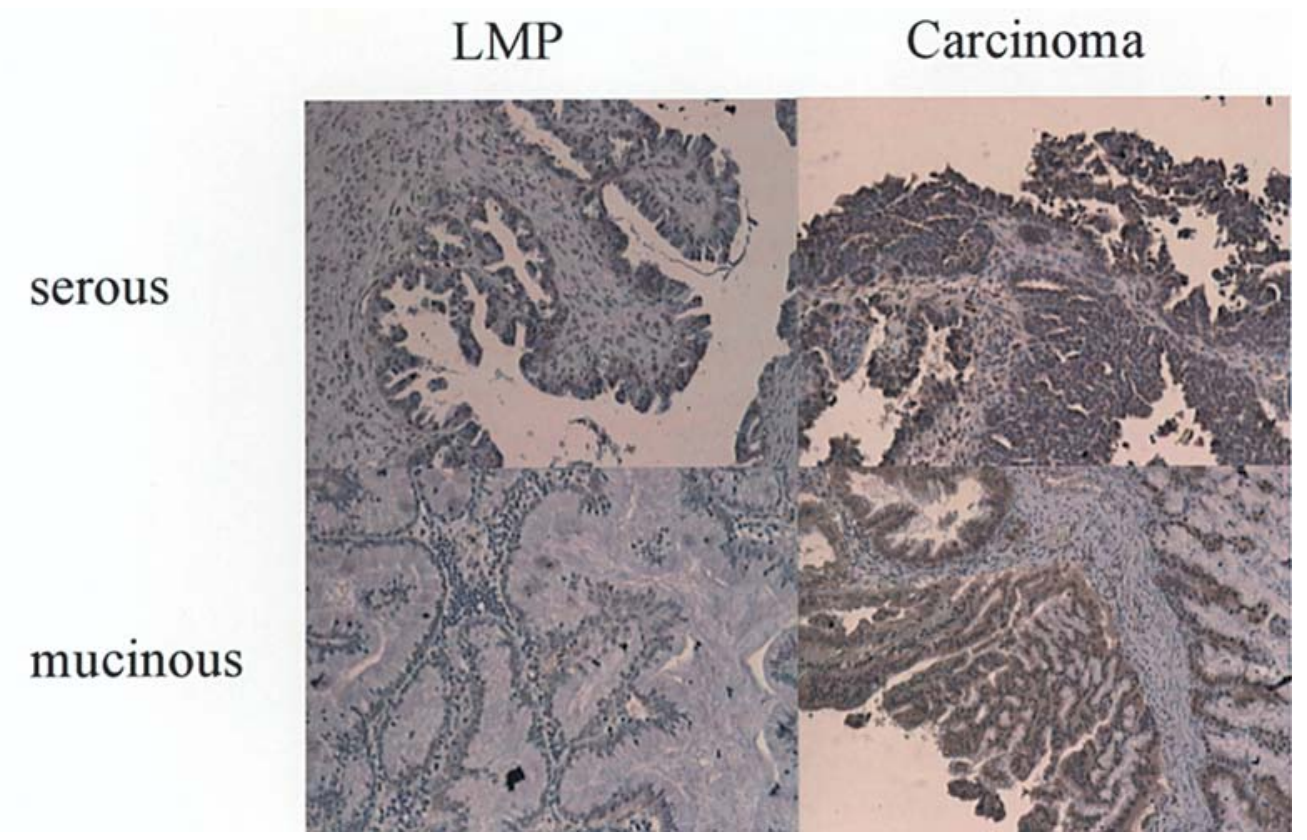

Figure 1. Immunohistochemical staining for Acrogranin in epithelial ovarian tumors. Acrogranin was strongly stained in the epithelial lesion of serous or mucinous ovarian cancer. On the other hand, in a low malignant potential tumor, Acrogranin was almost negative. LMP, low malignant potential.

from Santa Cruz Biotechnology) overnight at $4^{\circ} \mathrm{C}$, secondary antibody (biotinylated anti-goat $\mathrm{IgG}$ antibody) for $30 \mathrm{~min}$ at room temperature, and peroxidase-conjugated streptavidin for $30 \mathrm{~min}$ at room temperature. Slides were stained with DAB and then with hematoxylin as counter staining. Assessment was done by two independent pathologists, and scored as strong when $>50 \%$ of the tumor cells were stained strongly; as weak when $10-50 \%$ of tumor cells were stained at least weakly, and as negative if $<10 \%$ cells were stained.

Cell culture. IOSE cells were obtained and maintained as previously described (14). Briefly, ovarian surface epithelial cells were obtained during operation with written consent, and transfected with SV40 large T antigen (LT) and the human telomerase reverse transcriptase (hTERT). These cells were cultured in a 1:1 mixture of medium 199 and MCDB 105 (Sigma, St. Louis, MO). The human ovarian cancer cell lines A2780, SK-OV-3, and OVCAR-3 were maintained as previously reported (15).

Construction of retroviral vectors and gene transfection. The plasmid containing Acrogranin cDNA (pCMV-SPORT6Acrogranin) was obtained from Invitrogen Corporation (Carlsbad, CA, USA: clone ID 3457813). A retroviral vector pLHCX (Clontech; Franklin Lakes, NJ, USA) was converted to the Gateway destination vector by using the Gateway vector converting system (Invitrogen). Then a retroviral vector containing an expression cassette for Acrogranin (designated as pLHCX-Acrogranin) was constructed using Gateway technology. The final construct was transfected by lipofection into the packaging cell line, Amphopack293 (Clontech), and the supernatant containing amphotropic viruses was collected. Viruses were used to infect IOSE cells with $5 \mu \mathrm{g} / \mathrm{ml} 1,5-$ dimethyl-1,5-diazaundecamethylene polymethobromide
(Nakarai tesque; Kyoto, Japan), followed by selection with hygromycin B $(400 \mu \mathrm{g} / \mathrm{ml})$.

Reverse transcription PCR. Total RNA was extracted from cultured IOSE cells using Trizol reagent (Invitrogen). Reverse transcription PCR was performed with the One Step RT-PCR kit (Qiagen, Hilden, Germany) according to the manufacturer's instructions. PCR amplification of 25 cycles was performed as follows: denaturation at $94^{\circ} \mathrm{C}$ for $1 \mathrm{~min}$, annealing at $55^{\circ} \mathrm{C}$ for $1 \mathrm{~min}$, and extension at $72^{\circ} \mathrm{C}$ for $2 \mathrm{~min}$. For evaluation of Acrogranin mRNA expression, Actin was used as an internal control by multiplexing the Acrogranin and Actin-specific primers in each reaction. Primers used were: Acrogranin: forward 5'-TGG TTC ACA CCC GCT GCA-3', reverse 5'GTT GGG CAT TGG GCA GCA-3'; Actin: forward 5'-CCG CAA AGA CCT GTA CGC CA-3', reverse 5'-TGG ACT TGG GAG AGG ACT GG-3'.

WST-1 assay. Cells of $1 \times 10^{3}$ per each well were seeded in a 96-well plate (Iwaki, Tokyo, Japan) and cultured in $100 \mu 1$ of the same medium as mentioned above for $48 \mathrm{~h}$ at $37^{\circ} \mathrm{C}$ in a $5 \% \mathrm{CO}_{2}$. Cells were washed once and $100 \mu \mathrm{l}$ of the fresh medium and $10 \mu 1$ of Premix WST-1 (Takara Bio, Shiga, Japan) were added to each well and then cells were cultured for $2 \mathrm{~h}$ at $37^{\circ} \mathrm{C}$ in $5 \% \mathrm{CO}_{2}$. Absorbance was measured at $450 \mathrm{~nm}$ by EMax Precision microplate reader (Molecular Devices, CA, USA). The experiments were repeated 6 times.

Assay of anchorage independence. Colony formation of IOSE cells transfected with Acrogranin or empty vector in semisolid agar was assayed by suspending $4 \times 10^{4}$ cells in $800 \mu \mathrm{l}$ of $0.33 \%$ agarose and placing on the top of $800 \mu \mathrm{l}$ of solidified $0.5 \%$ agarose (13). Three weeks later, colonies $>50 \mu \mathrm{m}$ in 
Table I. Correlation between histological grading and Acrogranin expression in epithelial ovarian tumors.

\begin{tabular}{llcll}
\hline Histology & & Negative & Weak & Strong \\
\hline Carcinoma & Serous & $1 / 11$ & $4 / 11$ & $6 / 11$ \\
& Mucinous & $1 / 5$ & $1 / 5$ & $3 / 5$ \\
\multirow{2}{*}{ LMP } & Serous & $5 / 7$ & $2 / 7$ & $0 / 7$ \\
& Mucinous & $5 / 6$ & $1 / 6$ & $0 / 6$ \\
\hline
\end{tabular}

LMP, low malignant potential.

Table II. Tumor formation in nude mice.

\begin{tabular}{lc}
\hline Inoculated cells & Tumor formation \\
\hline IOSE/empty vector & $0 / 8$ \\
IOSE/Acrogranin & $8 / 8$ \\
\hline
\end{tabular}

diameter were counted as positive. The experiments were repeated 4 times.

Tumorigenicity assays. Female BALB/C athymic nude mice aged 6-8 weeks were purchased from CLEA Japan (Tokyo, Japan). The animals received proper care according to the rules of the Kyoto University Committee on Animal Care. Animal experiments were performed in compliance with the United Kingdom Coordinating Committee on Cancer Research (UKCCCR) Guidelines. Positive colonies formed in semisolid agar were seeded again in dishes and cultured for several days. Then these cells were collected and $2.5 \times 10^{7}$ cells were injected subcutaneously into nude mice. If subcutaneous mass was confirmed, the mice were sacrificed and the tumors were resected and examined microscopically. Cells were considered non-tumorigenic if the mouse failed to form a tumor within 4 months of injection.

Statistical analysis. For analysis of between-group differences, P-values were determined using the Mann-Whitney $U$ test and Chi-square test. A P-value $<0.05$ was considered significant.

\section{Results}

Immunohistochemical staining for Acrogranin in ovarian cancer. Sixteen cases of epithelial ovarian cancer as well as 13 cases of epithelial tumors of low malignant potential were stained for Acrogranin. Staining of Acrogranin in ovarian cancer is significantly stronger than that of borderline tumors $(\mathrm{P}<0.05)$, although the number of samples is relatively small (Fig. 1 and Table I).

Construction of Acrogranin transformed cell line. Acrogranin was tranefected into IOSE cells with retroviral vectors and transfectants were selected with hygromycin B. Expression of mRNA was confirmed by RT-PCR. Expression of Acrogranin

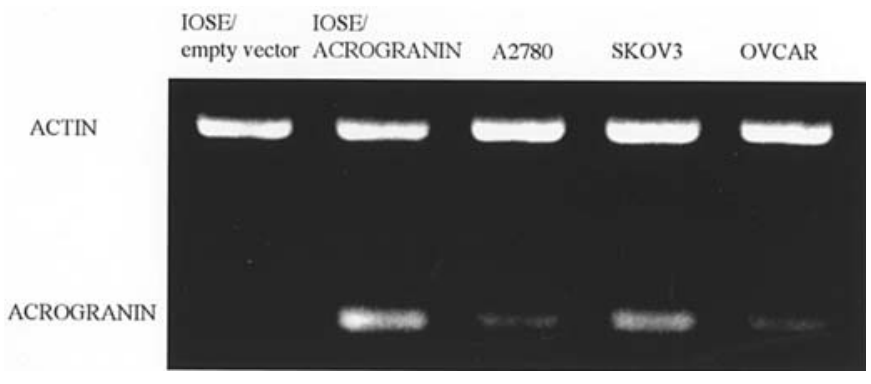

Figure 2. Confirmation of Acrogranin expression transfected in IOSE cells. Acrogranin mRNA expression was analyzed by RT-PCR (25 cycles). Ovarian carcinoma cell lines (A2780, SKOV3, OVCAR) also showed the expression of Acrogranin. ACTIN, internal control.

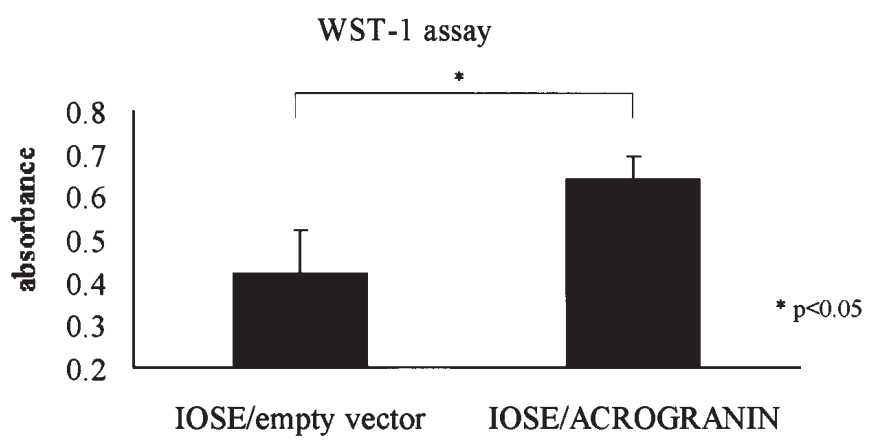

Figure 3. Cell proliferation analysis by WST-1 assay. The experiment was performed 6 times independently and the data show mean $\pm \mathrm{SE}$.

mRNA is strong in transfected IOSE cells as well as in human ovarian cancer cell lines A2780, SK-OV-3, and OVCAR-3. On the other hand, IOSE transfected with empty vector showed no expression of mRNA (Fig. 2).

Effect of Acrogranin transfection on the proliferation of IOSE. WST-1 assay was performed to evaluate whether transfected Acrogranin has an effect on proliferation activity. IOSE cells transfected with Acrogranin revealed significantly accelerated growth compared with empty vector-transfected IOSE cells $(\mathrm{P}<0.05)$ (Fig. 3). Anchorage-independent growth capacity was examined by soft agar clonogenicity assay. Anchorageindependent growth in IOSE cells was significantly enhanced by Acrogranin transfection as well $(\mathrm{P}<0.001)$ (Fig. 4)

Tumorigenicity of Acrogranin-transfected IOSE. In all the mice $(n=8)$ inoculated with IOSE cells transfected with Acrogranin, solid tumors were formed under the skin in 5 weeks (Fig. 5A). On the other hand, empty vector transformed IOSE cells did not form tumors in any of the mice within 4 months (Table II). Macroscopically tumors were present as very hard nodules. Histological study revealed a poorly differentiated-type of carcinoma (Fig. 5B) in which vascularization was prominent in the stroma (Fig. 5C). Immunohistostaining of Acrogranin was diffusely positive in the tumor cells (Fig. 5D).

\section{Discussion}

It is generally accepted that malignant tumor develops as a result of accumulation of genetic alterations, and in accordance 
A

IOSE/empty vector

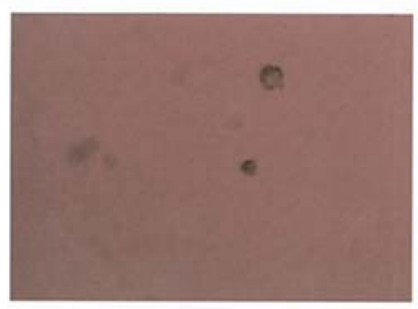

IOSE/ACROGRANIN

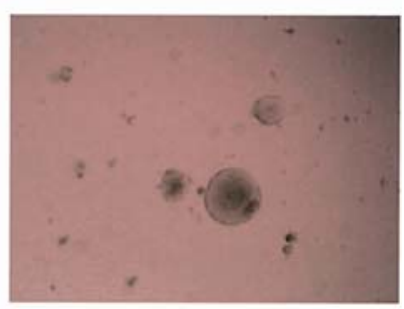

B

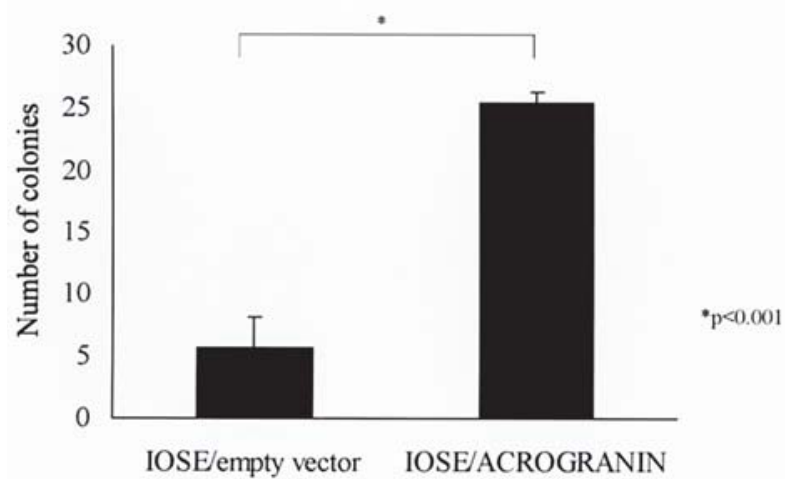

Figure 4. Anchorage-independent growth of Acrogranin-transfected IOSE cells. (A) Phase contrast microscopy of colonies in soft agar. (B) Number of colonies $>50 \mu \mathrm{m}$ was counted 20 days after seeding. The experiment was performed 4 times independently and the data show mean \pm SE.

with this, a number of gene abnormalities have been reported in various tumor types. However, it has been difficult to evaluate directly if such abnormalities are really responsible and inevitable in the course of cancer development. Hahn et al succeeded in transforming a human primary cell by the transfection of a defined combination of genes (16). Other similar studies have been conducted showing that in vitro transformation study is a useful method to evaluate whether a specific genetic event was essential for the development of malignant tumors.

Epithelial ovarian cancer is believed to derive from ovarian surface epithelium (OSE), a single layered epithelium covering the ovarian surface. We previously cultured OSE and transfected several genes in an attempt to evaluate the effect on the transformation of OSE. Transfection of hTERT and SV40 LT resulted in immortalization of OSE (IOSE), preserving its original phenotype such as the inability to form tumors in nude mice. Further transfection of c-ERBB2 or mutant HaRAS was sufficient for full malignant transformation presenting as tumor formation in nude mice (13). These data suggest that the method is a useful tool to assess the ability of specific genes to influence ovarian carcinogenesis. In this study, we focused on Acrogranin, a growth factor identified in highly tumorigenic PC murine-teratoma cells. Acrogranin is also highly expressed in cell lines and clinical specimens of ovarian cancer. According to Davidson et al, Acrogranin was detected in $95 \%$ of ovarian cancer specimens (11). In a comparative analysis of pooled library transcripts between
A

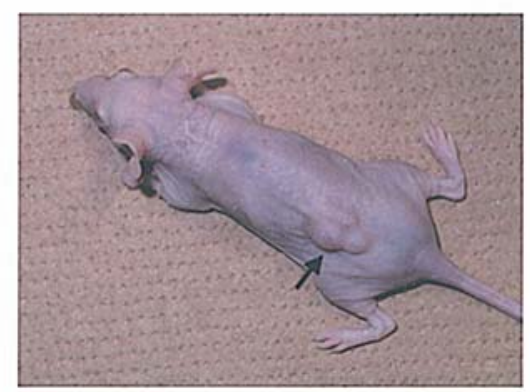

B

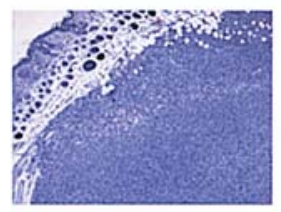

C

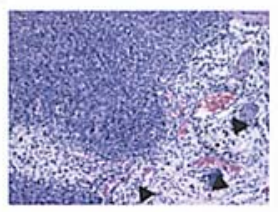

D

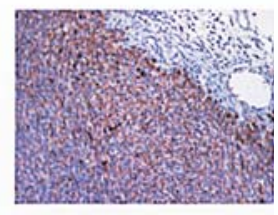

ACROGRANIN(+)
Figure 5. Tumor formation in nude mice and histological analysis. (A) The appearance of a typical tumor with Acrogranin-transfected IOSE cells (arrow). (B) Solid and poorly differentiated-type of carcinoma was formed in the inoculated lesion. (C) Vascularization was prominently observed in the stromal lesion (arrow head). (D) Immunohistochemical staining for Acrogranin was diffusely positive in the tumor.

ovarian border-line tumor and invasive carcinoma, whereas Jones et al (12) reported that Acrogranin was expressed only in the latter. In our limited study on human specimens of ovarian cancer and borderline tumors, Acrogranin protein is more strongly expressed in cancer specimens. These data suggest that Acrogranin serves as an autocrine growth factor for epithelial ovarian cancer, and it is plausible that Acrogranin is also related to ovarian cancer development.

Therefore, we attempted to obtain more direct evidence that Acrogranin contributes to the development of ovarian cancer. Acrogranin was transfected into immortalized OSE cells (IOSE) that were previously established by introduction of hTERT and SV40 LT to cultured OSE. Overexpression of Acrogranin in IOSE by retrovirus-mediated transfection resulted in significant promotion of cell growth and enhanced colony formation in soft agar compared with empty vectortransfected IOSE cells. It has been reported that induction of Acrogranin in SW-13 human adrenal carcinoma cells resulted in increased cell proliferation and enhanced clonogenicity. On the other hand, transfection of ovarian cancer cells with antisense Acrogranin reduced cell growth and Sphase fraction, and resulted in loss of density-independent growth (12). Our data indicate that Acrogranin overexpression has a similar cell-activating effect on phenotypically normal human cells as well as on cancer cells.

In terms of tumorigenicity in vivo, transfection of Acrogranin into hTERT and SV40 LT-immortalized OSE cells resulted in tumor formation in athymic nude mice. Although it was reported that overexpression of Acrogranin in a cancer cell line (SW-13) augmented the tumorigenicity in nude mice (17), this is the first study showing that Acrogranin endows tumorigenicity to phenotypically normal 
cells which originally did not form tumors in nude mice. Studies on in vitro-malignant transformation have revealed that, in order to transform primary human cells, the following four signals are necessary: 1) maintenance of telomere length by hTERT expression, 2) perturbation of p53 and RB by SV40LT expression or other methods, 3) perturbation of PP2A by SV40 ST expression or other methods, 4) constitutive RAS signaling by transfection of the oncogenic allele of RAS (18-21). In general, signals from growth factors are transmitted through tyrosine kinase-type receptors to RAS (22). In this view, it is expected that growth factor signals may substitute for oncogenic RAS transfection. As we previously reported, ovarian surface epithelial cells immortalized by co-expression of hTERT and SV40 are transformed by c-ERBB2 instead of oncogenic RAS (13). However, it has to be clarified if overexpression of growth factor itself can substitute for oncogenic RAS signal. Acrogranin activates the MAP kinase and phosphatidyl inositol-3 kinase (PI3K) signaling cascades (23). Activated PI3K can substitute, at least in part, for oncogenic RAS signal in de novo transformation (24). Hence, it is one of the possible mechanisms that Acrogranin exert oncogenicity via PI3K activation by substituting RAS signaling. However, we do not have direct evidence for this, and other possibilities cannot be excluded.

In summary, our data show that the combination of hTERT, SV40 LT, and Acrogranin gene transfection into human ovarian surface epithelium induced tumorigenicity. This is evidence that a growth factor plays a direct role in malignant transformation in human cells. It also suggests that Acrogranin has a potent oncogenic property in ovarian carcinogenesis, and is thus possibly an important molecular target in therapy for this disease.

\section{Acknowledgements}

We thank Miss Michiko Muraoka for her great contribution as a laboratory technician. This study was supported by Grant-in-Aid for Scientific Research to M.M. (17591732), S.F. (15209057), K.T. (17659514) and T.H. (17591729) from Japan Society for the Promotion of Science.

\section{References}

1. Cross M and Dexter TM: Growth factors in development, transformation, and tumorigenesis. Cell 64: 271-280, 1991.

2. Aaronson SA: Growth factors and cancer. Science 254: 1146-1153, 1991.

3. Bhandari V, Palfree RG and Bateman A: Isolation and sequence of the granulin precursor cDNA from human bone marrow reveals tandem cysteine-rich granulin domains. Proc Natl Acad Sci USA 89: 1715-1719, 1992.

4. Zhou J, Gao G, Crabb JW and Serrero G: Purification of an autocrine growth factor homologous with mouse epithelin precursor from a highly tumorigenic cell line. J Biol Chem 268: 10863-10869, 1993.

5. Daniel R, Daniels E, He Z and Bateman A: Progranulin (acrogranin/PC cell-derived growth factor/granulin-epithelin precursor) is expressed in the placenta, epidermis, microvasculature, and brain during murine development. Dev Dyn 227: 593-599, 2003.
6. He Z, Ong CH, Halper $\mathrm{J}$ and Bateman A: Progranulin is a mediator of the wound response. Nat Med 9: 225-259, 2003.

7. Liau LM, Lallone RL, Seitz RS, Buznikov A, Gregg JP, Kornblum HI, Nelson SF and Bronstein JM: Identification of a human glioma-associated growth factor gene, granulin, using differential immuno-absorption. Cancer Res 60: 1353-1360, 2000.

8. Serrero G and Ioffe OB: Expression of PC-cell-derived growth factor in benign and malignant human breast epithelium. Hum Pathol 34: 1148-1154, 2003.

9. Pan CX, Kinch MS, Kiener PA, Langermann S, Serrero G, Sun L, Corvera J, Sweeney CJ, Li L, Zhang S, Baldridge LA, Jones TD, Koch MO, Ulbright TM, Eble JN and Cheng L: PC cell-derived growth factor expression in prostatic intraepithelial neoplasia and prostatic adenocarcinoma. Clin Cancer Res 10: 1333-1337, 2004.

10. Cheung ST, Wong SY, Leung KL, Chen X, So S, Ng IO and Fan ST: Granulin-epithelin precursor overexpression promotes growth and invasion of hepatocellular carcinoma. Clin Cancer Res 10: 7629-7636, 2004

11. Davidson B, Alejandro E, Florenes VA, Goderstad JM, Risberg B, Kristensen GB, Trope CG and Kohn EC: Granulin-epithelin precursor is a novel prognostic marker in epithelial ovarian carcinoma. Cancer 100: 2139-2147, 2004.

12. Jones MB, Michener CM, Blanchette JO, Kuznetsov VA, Raffeld M, Serrero G, Emmert-Buck MR, Petricoin EF, Krizman DB, Liotta LA and Kohn EC: The granulin-epithelin precursor/PC-cell-derived growth factor is a growth factor for epithelial ovarian cancer. Clin Cancer Res 9: 44-51, 2003.

13. Kusakari T, Kariya M, Mandai M, Tsuruta Y, Hamid AA, Fukuhara K, Nanbu K, Takakura K and Fujii S: C-erbB-2 or mutant Ha-ras induced malignant transformation of immortalized human ovarian surface epithelial cells in vitro. Br J Cancer 89: 2293-2298, 2003

14. Kuroda H, Mandai M, Konishi I, Tsuruta Y, Kusakari T, Kariya M and Fujii S: Human ovarian surface epithelial (OSE) cells express $\mathrm{LH} / \mathrm{hCG}$ receptors, and hCG inhibits apoptosis of OSE cells via up-regulation of insulin-like growth factor-1. Int J Cancer 91: 309-315, 2001.

15. Tsuruta Y, Mandai M, Konishi I, Kuroda H, Kusakari T, Yura Y, Hamid AA, Tamura I, Kariya M and Fujii S: Combination effect of adenovirus-mediated pro-apoptotic bax gene transfer with cisplatin or paclitaxel treatment in ovarian cancer cell lines. Eur J Cancer 37: 531-541, 2001.

16. Hahn WC, Counter CM, Lundberg AS, Beijersbergen RL, Brooks MW and Weinberg RA: Creation of human tumour cells with defined genetic elements. Nature 400: 464-468, 1999.

17. He Z and Bateman A: Progranulin gene expression regulates epithelial cell growth and promotes tumor growth in vivo. Cancer Res 59: 3222-3229, 1999.

18. Rangarajan A, Hong SJ, Gifford A and Weinberg RA: Speciesand cell type-specific requirements for cellular transformation. Cancer Cell 6: 171-183, 2004.

19. Akagi T: Oncogenic transformation of human cells: shortcomings of rodent model systems. Trends Mol Med 10: 542-548, 2004.

20. Bocchetta M and Carbone M: Epidemiology and molecular pathology at crossroads to establish causation: molecular mechanisms of malignant transformation. Oncogene 23: 6484-6491, 2004.

21. Zhao JJ, Roberts TM and Hahn WC: Functional genetics and experimental models of human cancer. Trends Mol Med 10: 344-350, 2004.

22. Campbell PM and Der CJ: Oncogenic Ras and its role in tumor cell invasion and metastasis. Semin Cancer Biol 14: 105-114, 2004.

23. Zanocco-Marani T, Bateman A, Romano G, Valentinis B, He ZH and Baserga R: Biological activities and signaling pathways of the granulin-epithelin precursor. Cancer Res 59: 5331-5340, 1999.

24. Zhao JJ, Gjoerup OV, Subramanian RR, Cheng Y, Chen W, Roberts TM and Hahn WC: Human mammary epithelial cell transformation through the activation of phosphatidylinositol 3-kinase. Cancer Cell 3: 483-495, 2003. 